\title{
Modeling and assessment of the stress-strain state of above-ground pipelines at different types of compensation sections
}

\author{
Z.A.Besheryan, I.F. Kantemirov \\ Department of Oil and Gas Pipelines and Storage Facilities Construction and Repair, Faculty of \\ Pipeline Transportation, Ufa State Petroleum Technological University, Ufa, Russia
}

\begin{abstract}
The development of Russian fuel and energy complex in the short term is connected with the development of new hydrocarbon field in the permafrost zone and the need to build Arctic pipelines north of the 60th parallel. The ground-based structural scheme of pipeline laying is the most optimal while constructing trunk pipelines in permafrost areas in the Arctic and subarctic latitudes. The actual operating conditions of these systems are insufficiently studied. The above-ground pipeline in permafrost is in an complex stress-strain state. This study presents the results of the assessment of the stress-strain state of linearly extended above-ground pipelines at different compensation sections (triangular compensator; trapezoidal compensator; U-shaped compensator) under actual operating conditions. Using the finite element method on mathematical models, the dependences of the transverse displacements of the pipeline on movable supports and stresses arising in dangerous sections of the typical pipeline section during self-compensation of deformations on the variable design parameters of the system for various load combinations were established (the simulation was carried out in the ANSYS software package).
\end{abstract}

\section{Introduction}

Construction of modern pipelines and ensuring their operational reliability are priority tasks of the whole hydrocarbon trunk pipeline transport system. Quite often trunk pipelines cross permafrost areas on their way from the field to the consumer. Permafrost covers more than $60 \%$ of Russia's territory (more than 10 million square $\mathrm{km}$ ) and about $25 \%$ of the land[1]. Temperature below freezing point (of air and soil), the unstable bearing power of most of the soils when thawed, caused by an abrupt changein their mechanicalandphysical properties,are the main factors determining the specific conditionsin permafrost environment [2].

Nowadays, there is an indicative shift of hydrocarbon production centers to regions with difficult permafrost conditions in the Arctic and subarctic latitudes [3]. The above-ground structural layout of pipeline construction is most optimal for such regions. However, the actual operating conditions of linearly extended above-ground pipelines in permafrost and the factors the ensure the operational reliability of these systems are not well studied [4].

The determinants of the reliability of the above pipeline systems include protective calculation methods, optimal civil solutions, and rational installation schemes. At the same 
time, there is currently no scientifically substantiated calculation methodology for assessing the reliability of linearly extended above-ground pipelines on permafrost soils, taking into account real operating conditions under the influence of external (natural) and technological loads [5]. The reliability of pipeline systems directly depends on their stress-strain state (SSS).

In contrast to the construction of trunk pipelines in ordinary natural conditions, where well-studied and time-tested traditional solutions are used, in conditions complicated by the presence of permafrost soils, civil solutions for onshore oil pipeline construction have not been sufficiently studied $[1,6]$. This is primarily due to the insignificant experience in the construction of trunk oil pipelines on permafrost in Arctic latitudes, which has also been studied as part of this research. Local experience includes two projects of the last decade: the Zapolyarye - Purpe and the Vankorskoye - Purpeoil pipelines [7]. Foreign experience in the construction of above-ground oil pipelines under similar conditions can be attributed, perhaps, to the only project implemented in the United States in 1975-1977: the TransAlaska oil pipeline [8].

Given the above,the work aims to assess the stress-strain state of linearly extended above-ground pipelines with real operating conditions and to determine the optimal civil solutions from the condition of minimizing SSS when constructing them on permafrost soils.

\section{Methods}

Following the goal at this stage, the following research methods were used: analysis, comparison, generalization, and mathematical modeling in the software package ANSYS.

This paper presentsa study of the stress-strain state of an above-ground pipeline conducted on sample sections of a conditional 1000 pipeline located in Urengoy (YamaloNenets Autonomous Okrug, Russian Federation). The design of the above-ground sample section consists of two linear sections and a compensating section elbowed in the plan view and located between the linear sections.Elbow sections (compensators) can have different shapes: triangular, trapezoidal, and U-shaped (Figure 1) (P1-01.03 M-0109, 2016; STO Gazprom, 2009; STT-75.200.00-KTN-042-06, 2006). At this, supports of various designs, i.e., linear-sliding (LSS), free-sliding (FSS), and fixed (F), are used to ensure compensation of pipeline longitudinal deformation caused by temperature difference and internal pressure of the product (Figure 1) (STT-23.040.00-KTN-045-12, 2012). 

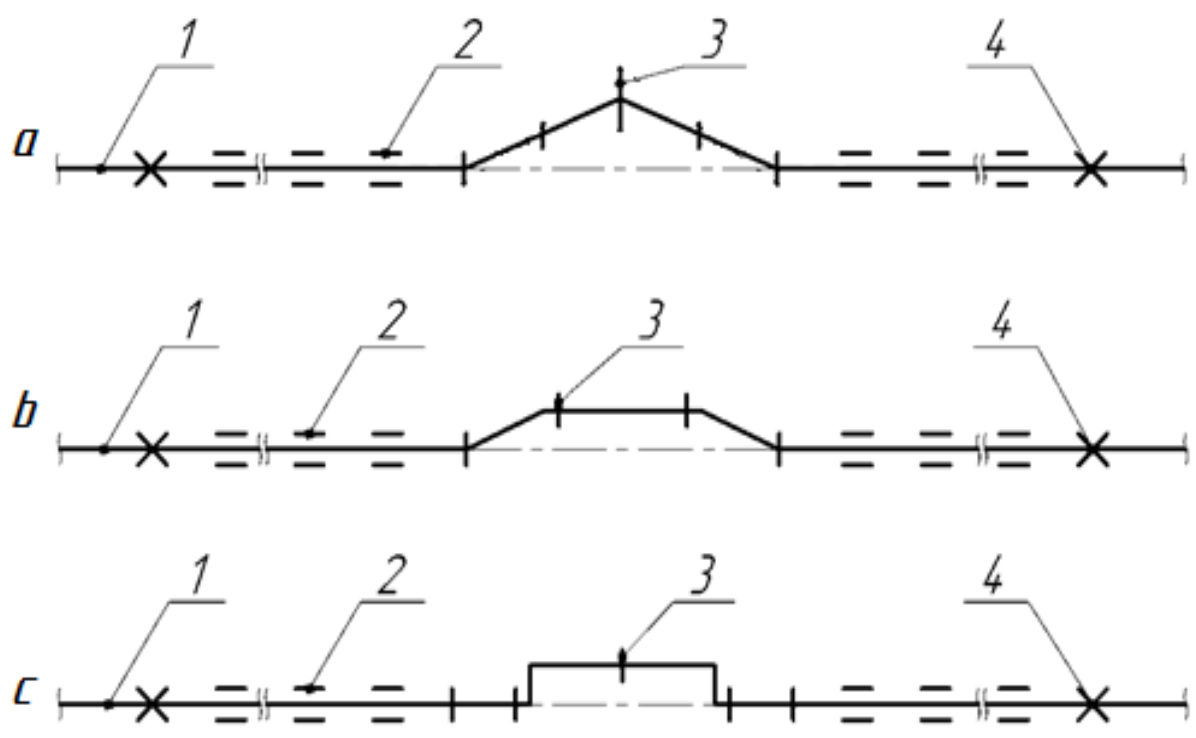

1 - pipeline; 2 - suspension linear-sliding support

3 - suspension free-sliding support; 4 - fixed support

Fig. 1. Scheme of straight-line laying of pipelines with curved compensation sections: triangular compensator (a); trapezoidal compensator (b); U-shaped compensator (c).

The friction forces appear when the pipeline is displaced during operation on the LSS and FSS sliding supports and prevent pipeline displacement in the horizontal plane (as they are directed oppositely). The value of the friction coefficient on the supports depends on the material of the rubbing surfaces and their actual condition [1]. The study was conducted for various combinations of rubbing surfaces (contact pair "pipeline - support"); Table 1 shows values of friction coefficients.

Table 1. Approximate values of the friction coefficient.

\begin{tabular}{lr}
\hline Sliding "pipeline - support" friction pair & Friction coefficient, Kfr \\
\hline Carbon steel to carbon steel (no corrosion) & 0.3 \\
Teflon to carbon steel (no corrosion) & 0.2 \\
Teflon to teflon, or polished stainless steel & 0.1 \\
Roller bearing or ball bearing & 0.05 \\
\hline
\end{tabular}

To estimate the stress-strained state of linearly extended above-ground pipelines under real operating conditions and to specify themost optimal design parameters of the system to minimize the stress-strain state, the author has performed mathematic simulation of sample sections of a conventional pipeline DN 1000 with compensators of various shapes (triangular, trapezoidal, and U-shaped) using the universal software system ANSYS (R 17.1). In contrast to the real experimental model, mathematical simulation allows to vary "real" design parameters of the system and simulate various load conditions that are most similar to real operating conditions of above-ground pipelinesin permafrost conditions.

Before the creation ofa mathematical simulation for the agreed trunk pipeline DN 1000 , theauthors have made calculations to specify the basic parameters of the aboveground pipeline bythe set of rules used for trunk pipelines in Russia (SP 36.13330.2012, 2013; SP 20.13330.2016, 2017). These calculations consider(1) the most indecorous combinations of assumed loads and impacts, (2) specifics of the region of construction, 
and(3) flow properties of the product (high-viscosity oil). Table 2 shows the key results of the calculations. The algorithm for constructing the model in the software package ANSYS, the advantages of the mathematical model, as well as verification of the results of finite element analysis, are described in the previous work of one of the authors[9].

Table 2. The basic input for simulation.

\begin{tabular}{cc}
\hline The basic input for calculations: & According to the current technical guidance document: \\
\hline $\begin{array}{c}\text { outside diameter pipeline: } 1020 \mathrm{~mm} \\
\text { tensile/yield strength- } 640 / 555 \mathrm{MPa} \\
\text { operating pressure: } 10 \mathrm{MPa}\end{array}$ & $\begin{array}{c}\text { wall thickness pipeline: } 28 \mathrm{~mm} \\
\text { the estimated weight of the pipeline, taking into account } \\
\text { section category: II }\end{array}$ \\
$\begin{array}{c}\text { the existing loads: } 16,02 \mathrm{kN} / \mathrm{m} \text {; } \\
\text { the product: high-viscosity oil }\end{array}$ & $\begin{array}{c}\text { possible subsidence of the intermediate supports at } \\
\text { permafrost: } 20 \mathrm{~m}\end{array}$ \\
\hline
\end{tabular}

At the next stage of the study, the authors have performeda series of calculations using finite element analysis to evaluate the stress-strain state of sample sections of the aboveground pipeline for various shapes of compensators and load conditions. To determine the best design solution for these systems, which is one of the factors ensuring the operational reliability of the above-ground pipeline, the following design parameters were changed during the simulation:

$\mathrm{L}$ is the shortest distance between the fixed supports. This parameter varies with a fixed step multiple of 41 ( 1 is the span between supports in linear sections).

$\mathrm{L}_{\mathrm{c}}$ isthe straight length of a compensator. For a triangular compensator, this parameter varies depending on the total number of spans in an elbow section. For the trapezoidal compensator, it varies depending on the number of spans in the upper part of the elbow section. For a U-shaped compensator, it varies depending on the size of the pipe section at the top of the elbow section.

$\alpha$ is the angle of inclination of the branch of the compensation section. This parameter changes against the background of the industrialization of the production of bent bends.

\section{Results}

Transverse displacements of pipeline and loads at the most dangerous sectional views caused by combinations of calculated loads and impacts when operating at long-distance pipelines were specified as the result of finite element analysis on mathematical simulations. Table 3 shows the basic examined variants of the simulated pipeline's exemplary sections.

Table 3.The basic examined variants of the simulated pipeline's samplesections.

\begin{tabular}{|c|c|c|c|c|c|}
\hline \multirow{2}{*}{$\begin{array}{l}\text { The shape of the } \\
\text { compensator } \\
\text { section }\end{array}$} & \multicolumn{3}{|c|}{$\begin{array}{l}\text { Design parameters of } \\
\text { asamplesection }\end{array}$} & \multirow{2}{*}{$\begin{array}{l}\text { Friction } \\
\text { coefficient, } \\
K f r\end{array}$} & \multirow{2}{*}{$\begin{array}{l}\text { Scheme of the simulated } \\
\text { section and results of finite } \\
\text { element analysis in ANSYS }\end{array}$} \\
\hline & $L, \mathrm{~m}$ & $L c, \mathrm{~m}$ & $\alpha$, degree & & \\
\hline \multirow{3}{*}{$\begin{array}{l}\text { Triangular- } \\
\text { shaped }\end{array}$} & $\begin{array}{l}237 \\
317 \\
397 \\
477\end{array}$ & 77 & 12 & 0.3 & Figure 2 \\
\hline & $L=L c+12 l$ & $\begin{array}{r}37 \\
77 \\
117 \\
\end{array}$ & 12 & 0.3 & Figure 3 \\
\hline & 317 & 77 & $\begin{array}{r}6 \\
12 \\
18\end{array}$ & 0.3 & Figure 4 \\
\hline
\end{tabular}




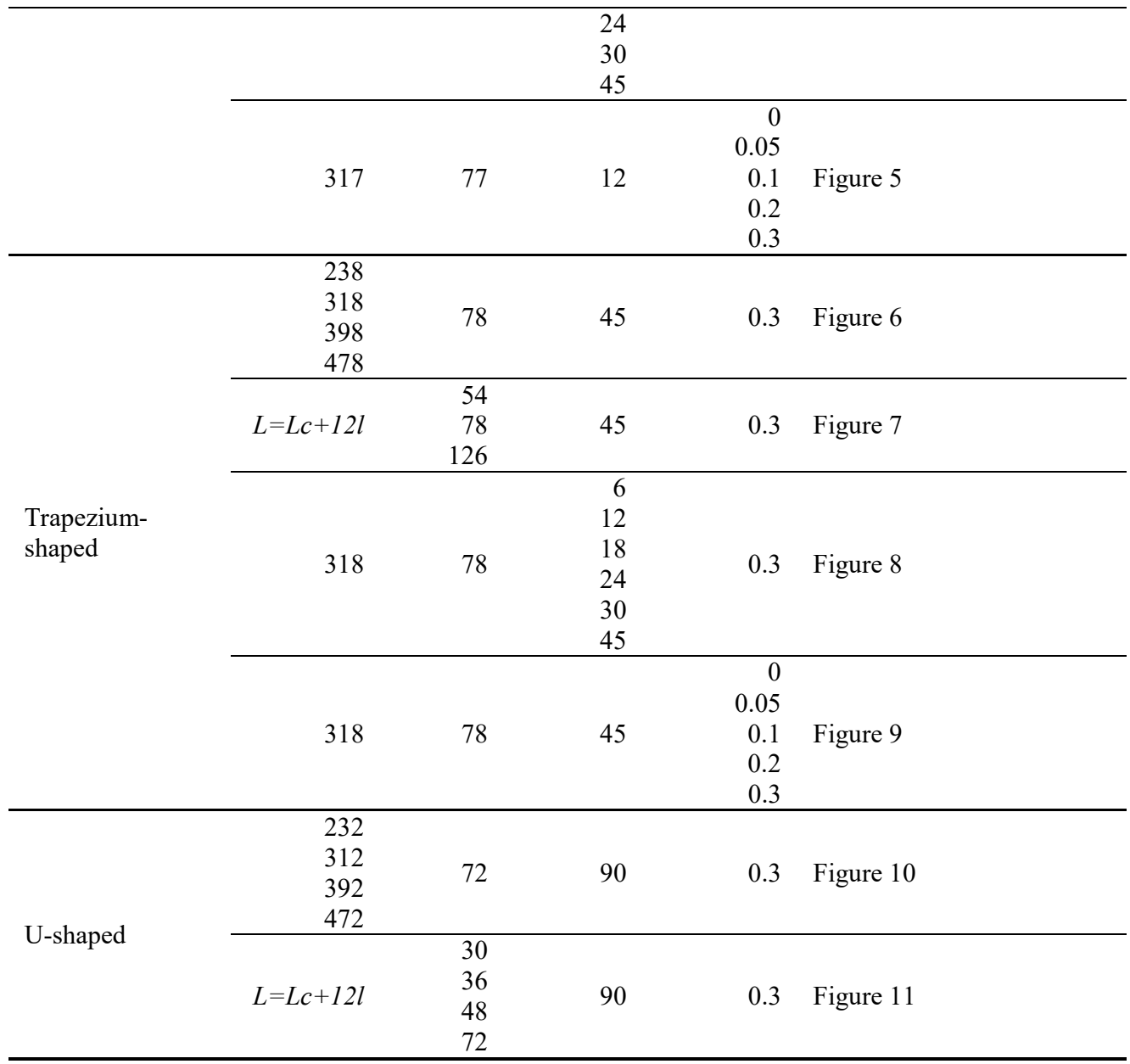

Processing the results allows establishing graphical dependencies of the studied parameters (displacements and stresses) from changes in the varied design parameters of samplesections and at different friction coefficients on the supports (Figures 2-11).

Figures 2-11 show the following designations followingthe regulations (SP 20.13330.2016, 2017; SP 36.13330.2012, 2013):

$\Delta \mathrm{t}$ : calculated temperature difference;

P: working pressure of the internal product;

DN: Piping Nominal Diameter;

$\mathrm{R}$ : bending radius of the pipeline (of the bent branch).

A thorough analysis of results gained from the research of the stress-strain state of an above-ground pipeline for sample sections with triangular-shaped compensators and trapezoidal compensators is described in previous works of the authors $[9,10]$. This study shows the main results of work simulation and assessment ofthe stress-strained state of above-ground pipelines on various forms of compensation sections and includes general conclusions. 


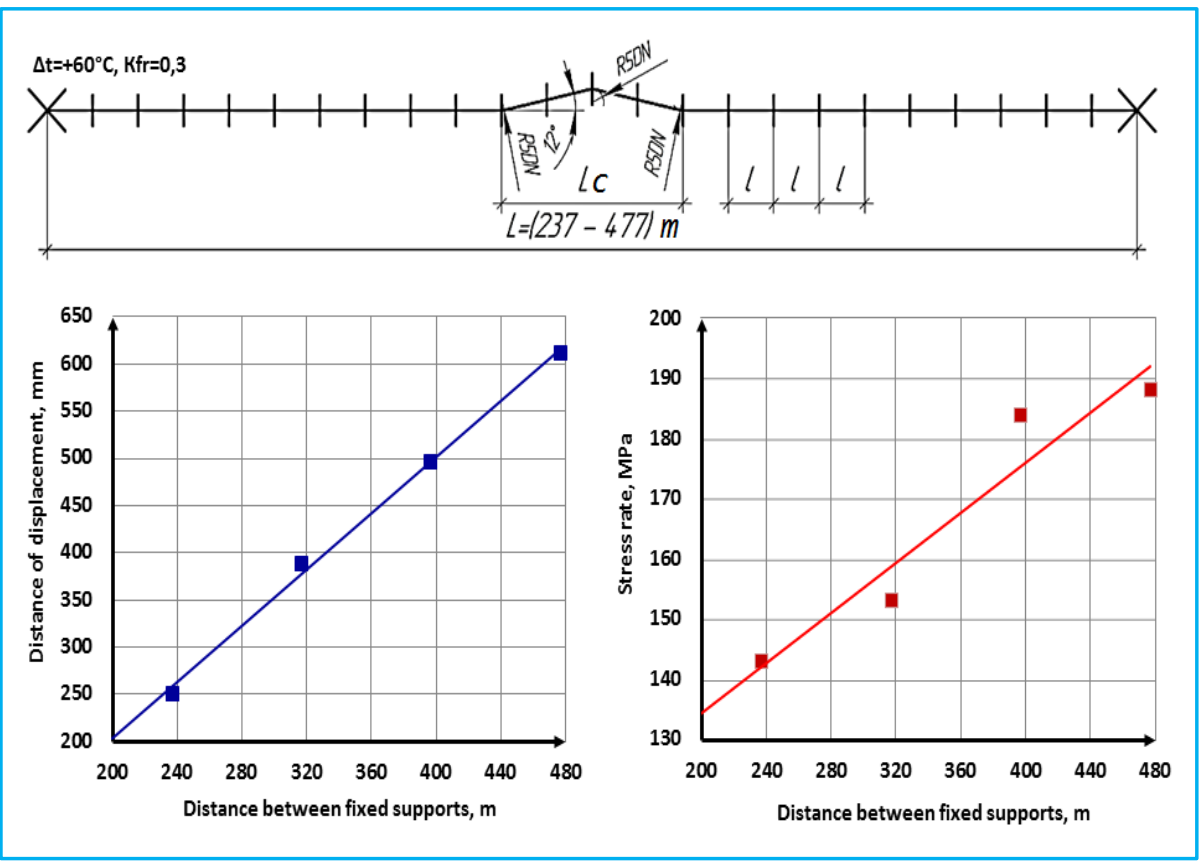

Fig. 2.Dependence of transverse displacements of the pipeline and stresses on the change in the value of $\mathrm{L}$ for a triangular compensator.

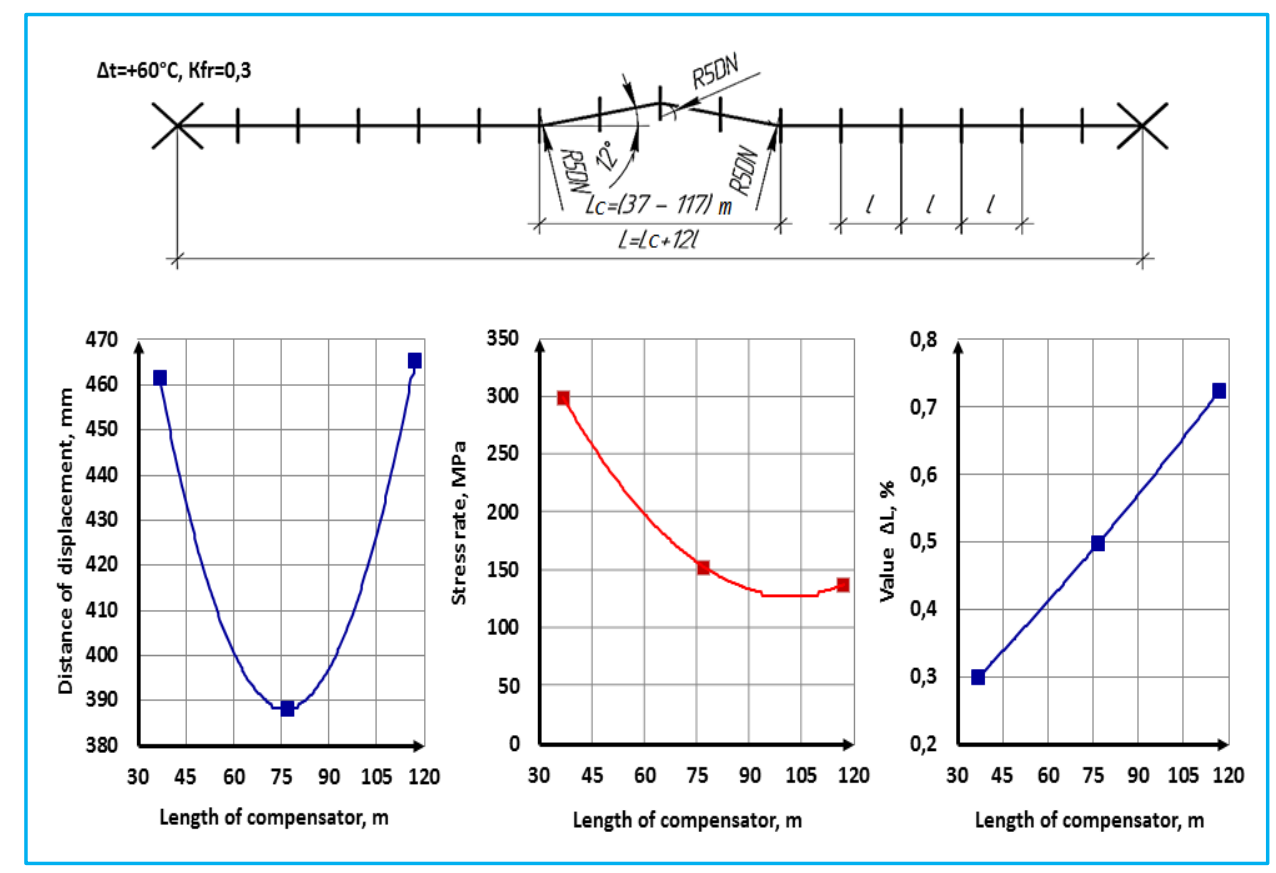

Fig. 3.Dependence of transverse displacements of the pipeline and stresses on the change in $\mathrm{L}_{c}$ for a triangular compensator. 


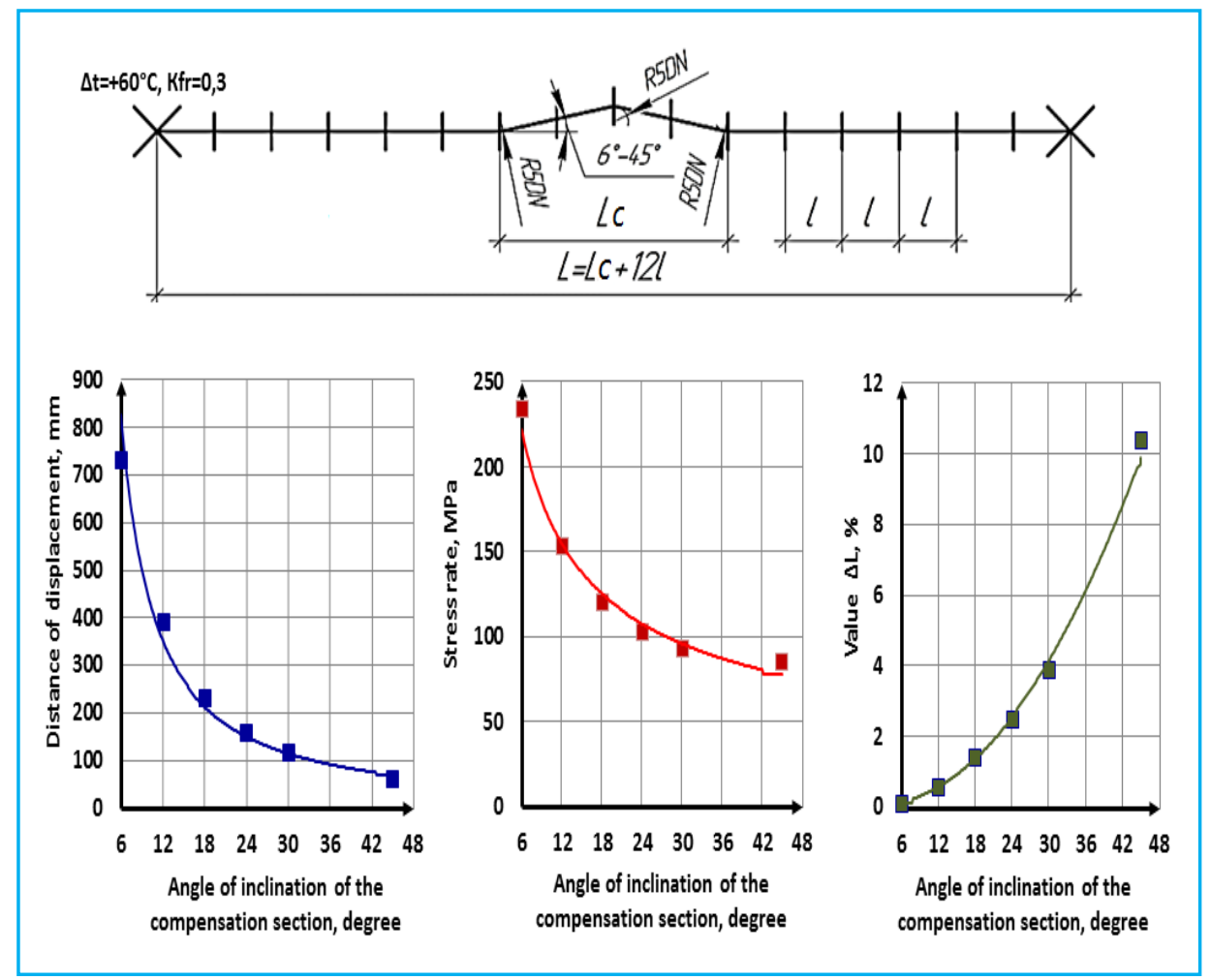

Fig.4.Dependence of transverse displacements of the pipeline and stresses on the change in the value of $\alpha$ for a triangular compensator.

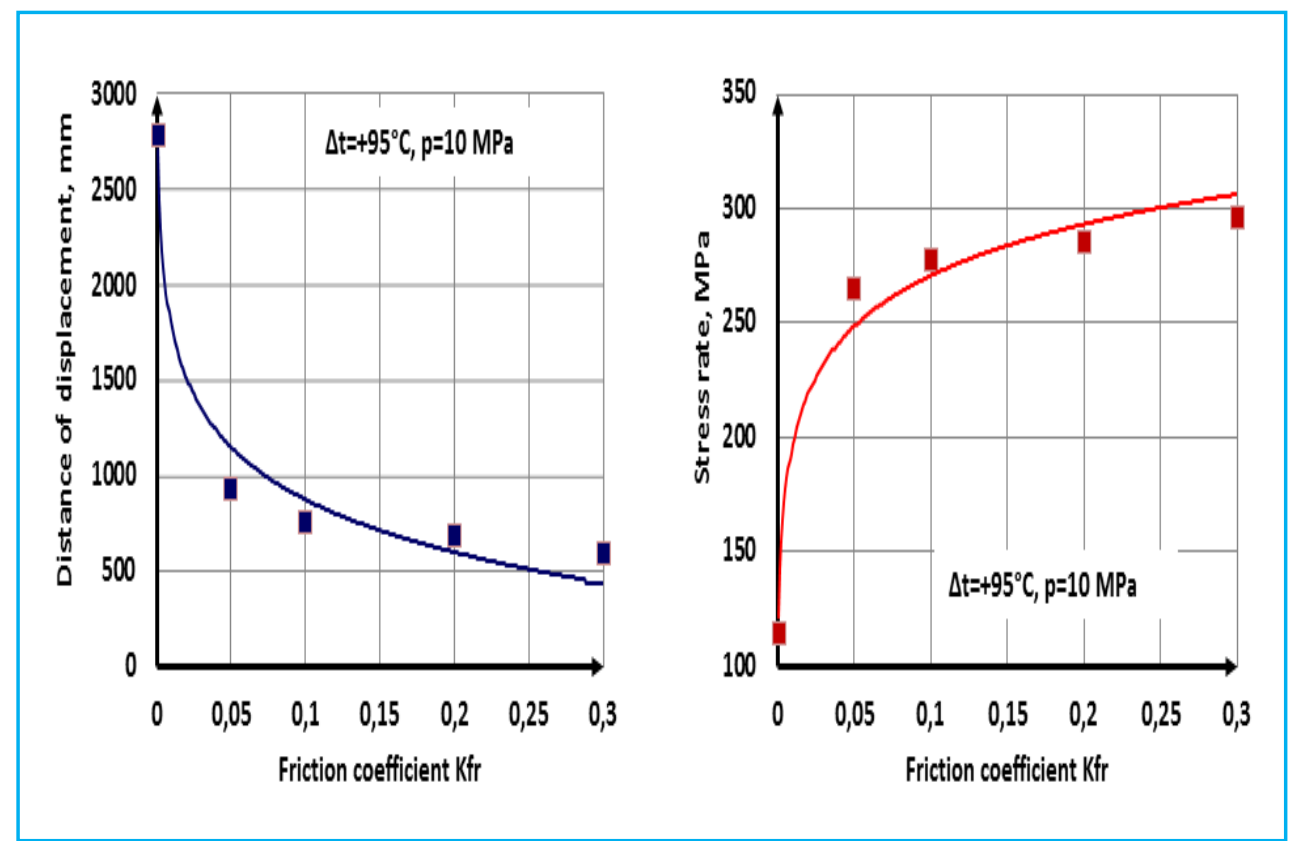

Fig. 5. Dependence of transverse displacements of the pipeline and stresses on the change in the value of $\mathrm{K}_{\mathrm{fr}}$ for a triangular compensator. 


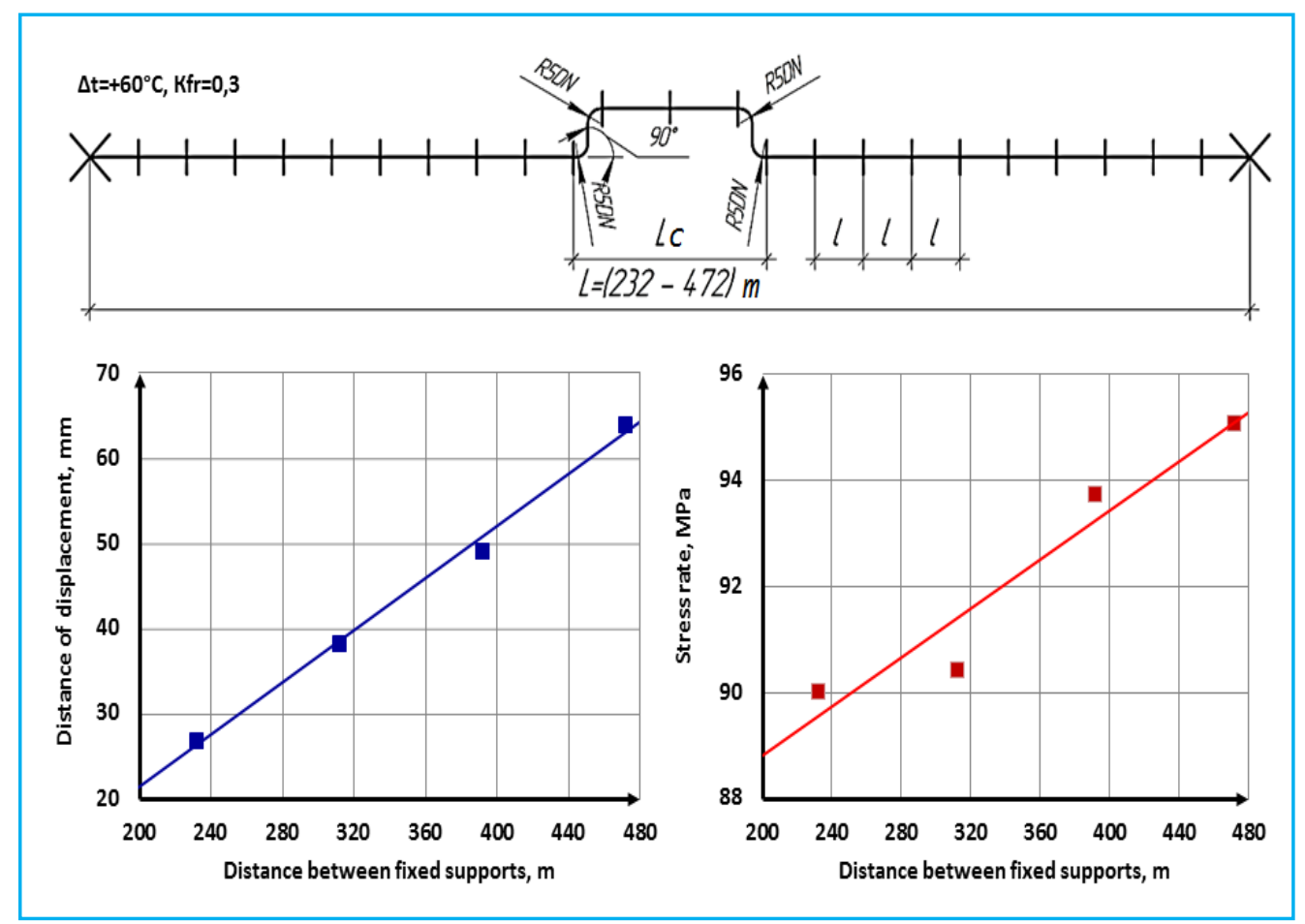

Fig. 6. Dependence of transverse displacements of the pipeline and stresses on the change in the value of $\mathrm{L}$ for the trapezoidal compensator.

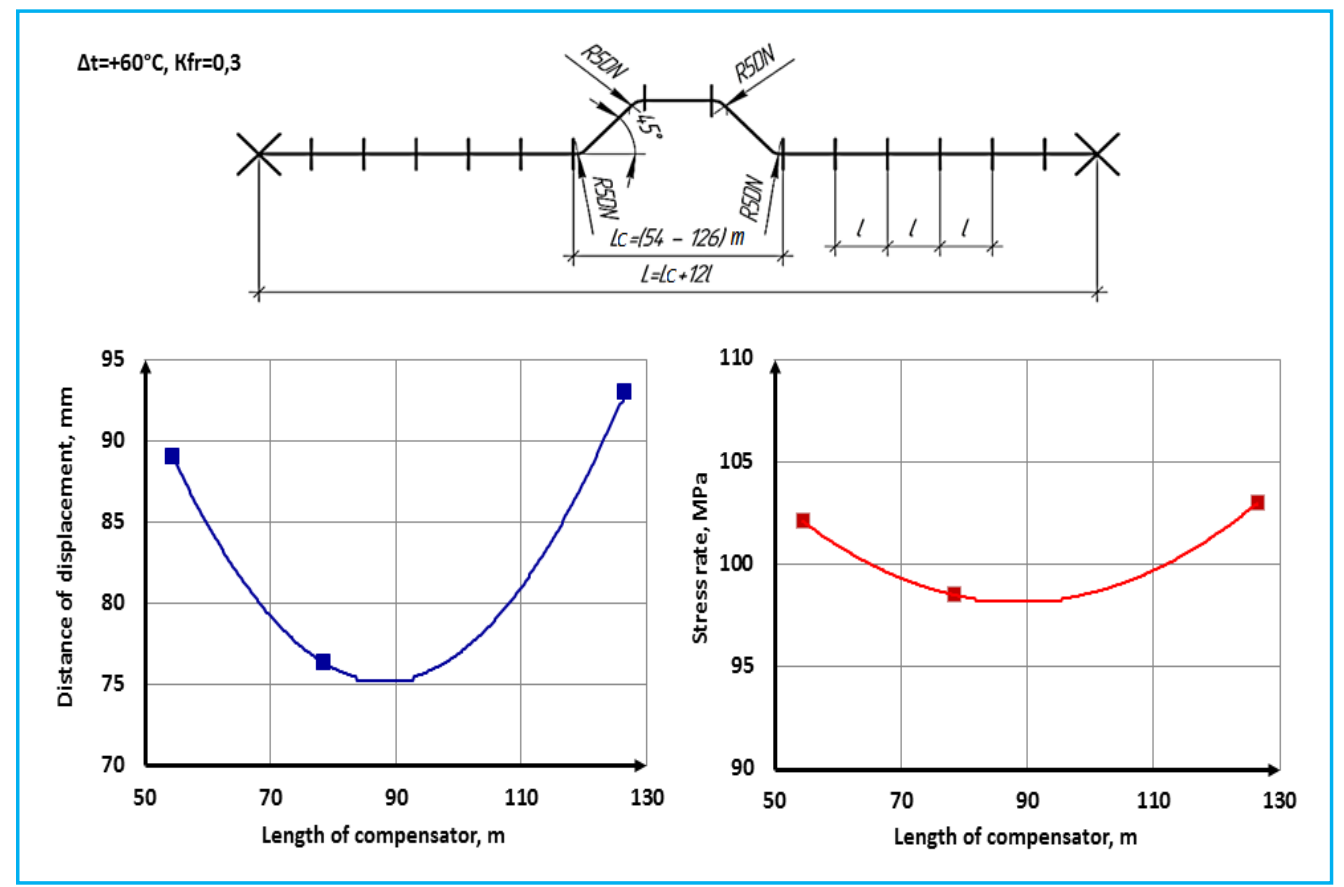

Fig. 7. Dependence of transverse displacements of the pipeline and stresses on the change in the value of Lc for a trapezoidal compensator. 


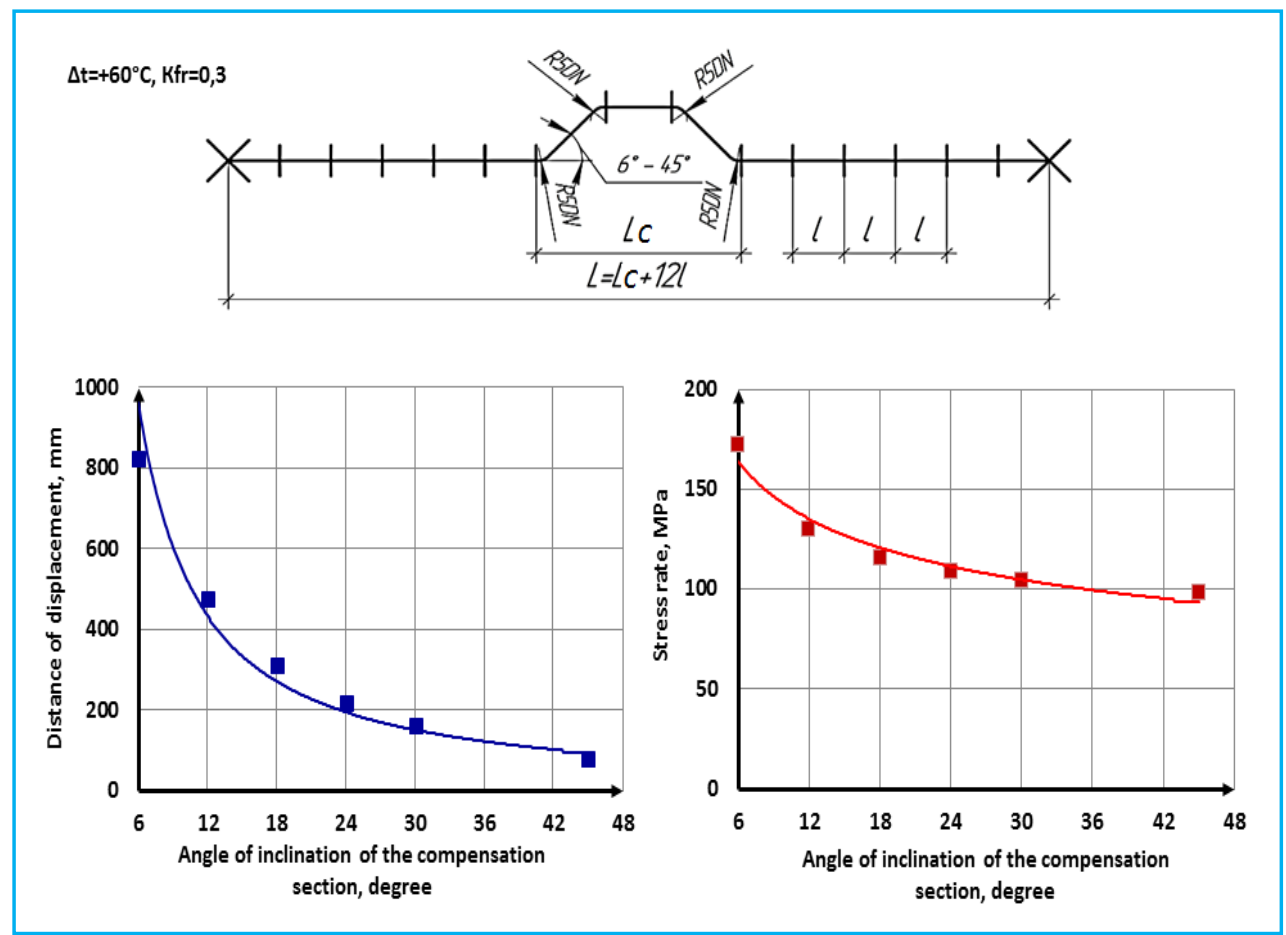

Fig. 8.Dependence of transverse displacements of the pipeline and stresses on the change in the value of $\alpha$ for the trapezoidal compensator.

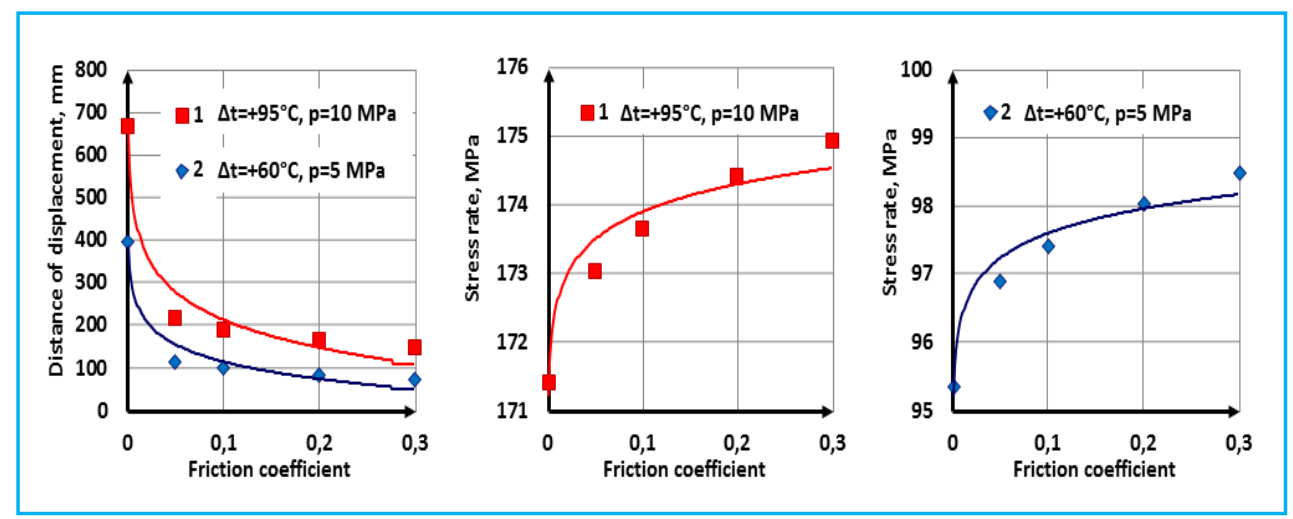

Fig. 9.Dependence of transverse displacements of the pipeline and stresses on the change in the value of $\mathrm{K}_{\mathrm{tr}}$ for the trapezoidal compensator at different values of the temperature difference and internal pressure of the product. 


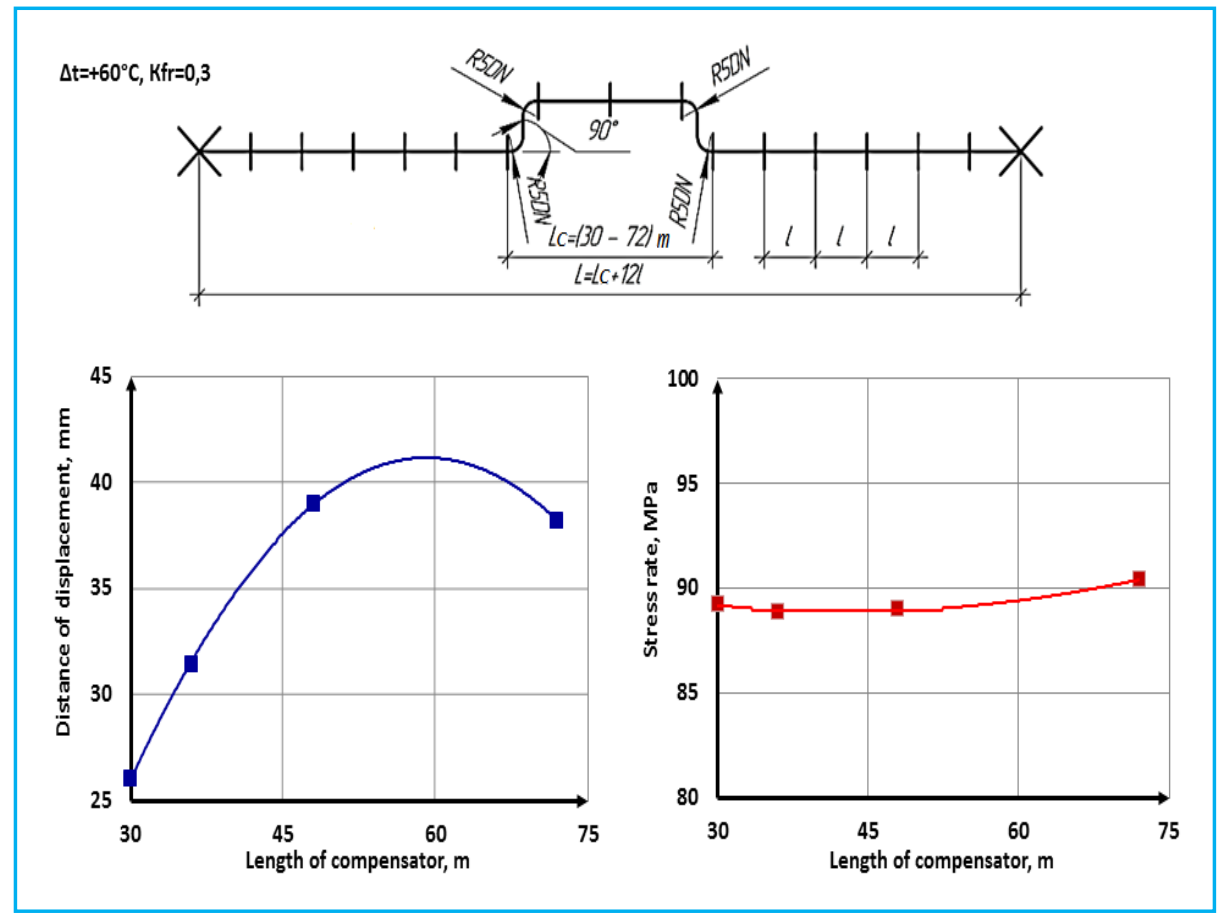

Fig. 10.Dependence of transverse displacements of the pipeline and stresses on the change in the value of $\mathrm{L}$ for the $\mathrm{U}$-shaped compensator.

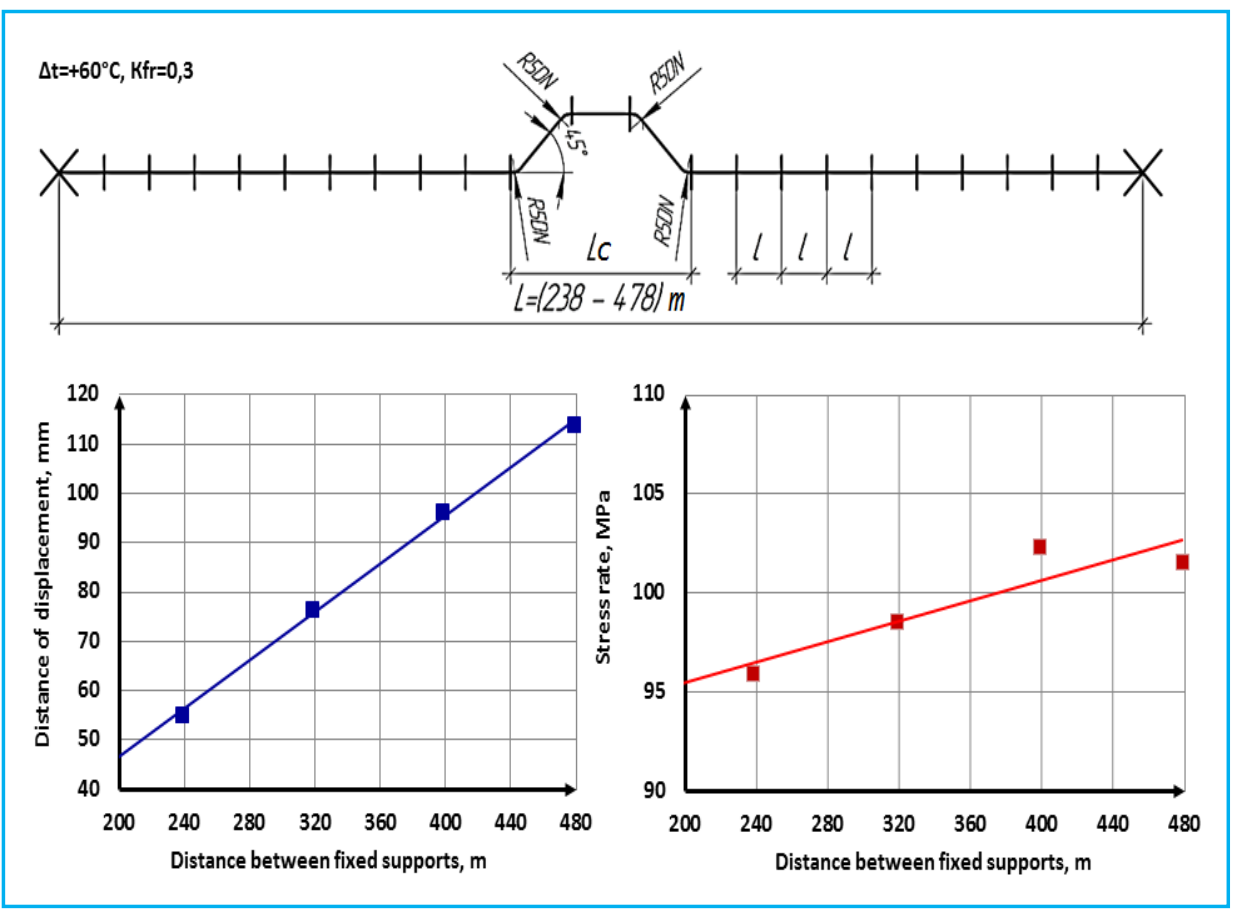

Fig. 11. Dependence of transverse displacements of the pipeline and stresses on the change in the value of $\mathrm{Lk}$ for the U-shaped compensator. 


\section{Discussion}

Friction forces on sliding supports have a significant influence on the compensation ability of the above-ground pipeline and characteristics ofthe stress-strain state in general. This was revealed earlier in the scope of experimental studies of above-ground pipeline deformability carried out at a smaller model of a sample pipeline section with a triangularshaped compensator $[11,12,13]$. Field observations conducted on real oil and gas trunk pipelines in difficult geological and climate conditions have proved the effect of friction forces on the deformation of the above-ground pipeline [14, 15]. However, consideration of these studies significantly complicates the traditional engineering evaluation. Therefore, it was decided to use a software-based method of calculation.

In studying the stress-strain state of typical sections of an above-ground oil pipeline by simulating their operations in the ANSYS software package, the following was established. Deformability of the above-ground pipeline, both when using a trapezoidal compensator and a triangular compensator, significantly depends on the friction coefficient at supports $\left(F_{c}\right)[11,12,13]$. However, a stress-strain state of a pipeline with a trapezoidal compensator depends less on change in the friction coefficient compared to a pipeline with a triangular compensator (Figures 5, 9).

It is important to note that simulation in the software package allows assessing the stress-strain state of linearly extended pipelines and has a number of advantages over field experiments. The mathematical model allows to:

- Investigate the separate and combined action of external (natural) and technological loads

- Set the initial unstressed position of the system

- Determine the values of displacements and stresses with sufficient accuracy

- Vary the design parameters of the system and change the support conditions

- Take into account random external natural factors (if necessary)

- Avoid side effects (skews and slopes of supports, their subsidence, surface defects, etc.)

- Repeat the experiment as many times as needed.

At present, foreign works do not pay active attention to this topic due to the lack of modern pipeline projects in the permafrost environment north of the 60th parallel in other oil-producing countries (Palmer 2011). Most of the relatively up-to-date scientific works on the design and construction of above-ground pipelines consider short sections - crossings over natural and artificial obstacles [4].

\section{Conclusions}

The study of the deformability and stress state of above-ground pipelines on permafrost soils by simulating the operation of a typical section of above-ground laying (a system of straight-line laying with compensating sections of different shapes) in a universal software system of finite element analysis - ANSYS made it possible to establish new dependences of lateral displacements of the pipeline on the supports and the maximum stresses in the hazardous sections on possible variables of the system design parameters and with different coefficients of friction on the supports. The obtained dependencies can be used in the development of a further substantiated software method for the calculation of above-ground pipelines.

Within the framework of this study, based on the SSS minimization condition, the optimal design solutions for typical sections of linearly extended pipelines are determined, which has practical value and can be used in the development of new projects for the construction of Arctic pipelines. 
As a result of the work simulation and evaluation of the stress-strain state of aboveground pipelines based on the example of sample sections of a conditional pipeline, DN 1000 with compensators of triangular, trapezoidal, and U-shaped forms, theauthors made the following conclusions (with the agreed field data).

1. Despite the compensator's form, its length $\left(\mathrm{L}_{\mathrm{c}}\right)$, and the friction coefficient on the supports (not shown in the figures so as not to overload them), the dependence of the stressstrain state of above-ground pipelines on the change of the length between fixed supports (L) has a clear-cut linear character (Figures 2, 6, 10). The value of the compensated length in the construction of linear above-ground pipelines should be taken as the maximum allowable according to the calculations, taking into account the terrain and turning angles of the pipeline.

2. From the condition of minimization of the complex stress-strain states of the aboveground pipeline, the optimal value of the length of a triangular compensator is $\mathrm{L}_{\mathrm{c}}=77 \mathrm{~m} \mathrm{(4}$ spans, Figure 3), of a trapezoidal compensator is $\mathrm{L}_{\mathrm{c}}=78 \mathrm{~m}$ (3 spans, Figure 7), and of a Ushaped, is $\mathrm{L}_{\mathrm{c}}=30 \mathrm{~m}$ (3 spans, Figure 11).

3. To ensure thehigh compensation ability of above-ground trunk pipeline, the justified value of maximum pipeline displacements in the plan view, and stresses in hazardous sectional views, the optimum value of the slope of a compensator branch relative to straight section $(\alpha)$ for the system with a triangular-shaped compensator is $15^{\circ}-21^{\circ}$ (Figure 4), with a trapezoidal $-45^{\circ}$ (Figure 8 ).

Comparative analysis of the considered forms of compensators showed that the trapezoidal shape is more optimal for the above-ground construction of pipelines in permafrost conditions. This compensator shape should be used as a basis for further improvement of the design solutions of the system taking into account real working conditions of above-ground trunk pipelines in permafrost in the Arctic and subarctic latitudes.

\section{References}

1. I.P. Petrov, V.V. Spiridonov, Overhead Laying of Pipelines(Moscow: Nedra Publ., 1973)

2. A.K. Dercakyan, N.P. Vasil'ev, Construction of Pipelines in Swamps and Permafrost Soils(Moscow: Nedra Publ., 1973)

3. D.F. Bikmukhametov, G.E. Korobkov, A.P. Yanchushka, Features of Aboveground Pipe-line Compensation Part Stress-Deformed Study at Permafrost. Modern Applied Science,9(8): 204-212(2015).

4. V.V. Smirnov, Y.D. Zemenkov, The Appliance of the Boundary Element Method for Calculation of the Stress-Deformed State of Above-Ground Pipeline in Permafrost. Pipeline Transport (theory and practice), 4 (38): 18-23 (2013).

5. D. Opeyemi, S.A. Timashev, A.V. Bushinskaya, E. Patelli, M. Beer, Method of Reliability Assessment of Arctic Pipelines in the Space of Loads. Russian Journal of Construction Science and Technology,3 (1): 49-59(2017).

6. A. Palmer, Arctic,Pipelines and the Future. Journal of Pipeline Engineering,10(2): 117-125(2011).

7. Y.V. Lisin, A.E. Soschenko, V.V. Bondarenko, and others. The main technical solutions for the construction of pipeline supports for the sections of the above-ground laying of the Zapolyarye - OPS Purpe pipeline system. Pipeline transport (theory and practice),6 (40): 4-7,(2013).

8. J. Tiratsoo, Trans Alaska Pipeline System. PipelinesInternationalISSUE, 004,(2010). 
9. L.I. Bykov, Z.A. Besheryan, Study of Deformation and Stress State of Overhead Pipelines on the Permafrost Soils. Problems of Gathering, Treatment, and Transportation of Oil and Oil Products, 2 (118): $81-90$ (2019).

10. L.I. Bykov, I.F. Kantemirov, Z.A. Besheryan, Study of stress-strain state of overhead pipelines with compensative sections of various forms. Problems of Gathering, Treatment, and Transportation of Oil and Oil Products,6 (122): 115-125 (2019).

11. V.Y. Magalif, V.V. Spiridonov, V.P. Cherny, Self-Compensation of Pipelines with Regard to Friction. (Moscow: VNIIENGazprom Publ.(in Russian),1972).

12. V.V. Spiridonov, V.P. Cherny, On the Deformations of the Overhead Piping System.(Moscow: VNIIENGazprom Publ.(in Russian),1971).

13. V.V. Spiridonov, V.P. Cherny, Modelling of Overhead Pipelines. (Moscow: VNIIENGazprom Publ.(in Russian), 1972).

14. V.V. Spiridonov, V.V. Lemekhanov, Full-Scale Studies of the Stress State and Deformations of the Above-Ground Gas Pipeline. Papers of VNIIST, 15,1963.

15. V.V. Harionovskiy, Increasing the Strength of Gas Pipelines in Difficult Conditions. (Moscow: Nedra Publ. (in Russian),1990). 